\title{
Integral risk management by pension funds in a fair value framework
}

Received (in revised form): 12th November, 2002

\section{Eduard H. M. Ponds}

works for ABP Pension Fund in the Netherlands, in the Risk Policy Department. He is responsible for asset and liability management. He also teaches actuarial science at the University of Amsterdam, Department of Economics and Econometrics. $\mathrm{He}$ has a PhD in economics from University of Tilburg. His main areas of interest are defined benefit schemes and intergenerational risksharing.

\section{Fons Quix}

also works for ABP Pension Fund in the Netherlands, in the Risk Policy Department. He is responsible for risk measurement and risk control on the level of the pension fund.

\begin{abstract}
Pension funds worldwide, for instance in the UK and the Netherlands, will increasingly adopt the fair value approach. The aim of this paper is to derive an integral risk management framework for pension funds, based on fair value principles. The point of reference is a typical defined benefit plan with indexed liabilities, where the main sources of risk are the long-term fluctuations in prices driving the value of the plan's assets and the fluctuations in the discount and inflation rates that determine the value of the liabilities. Mismatch risk is identified as the central risk measure for integral risk management. The fair value approach contributes in clarifying the long-term advantages of a pension fund scheme; however, the approach also contributes in revealing its main weakness: a high exposure to mismatch risk and hence a large risk of underfunding in the short term. A typical pension fund usually fails to be explicit on the issue of risk bearing. Therefore, it is not clear which of the stakeholders has to meet up a funding shortage. Three options to handle short-term risk are discussed. First, creating a floor by investing substantially in index-linked bonds. Secondly, holding a high solvency margin to absorb a fall in asset prices. The third option, preferred by the authors, is to state the so-called pension deal so that it is clear which of the stakeholders is participating in the risk of underfunding as well as overfunding, and to what extent. Such a deal will assist in preventing potential conflicts between the stakeholders about the allocation of benefits and costs. The pension fund management and its stakeholders will only obtain good insight into the benefits and costs if the pension fund contract is a transparent and complete contract. Fair value principles contribute to these goals of transparency and completeness.
\end{abstract}

Keywords: pension funds; risk management; ALM; fair value; pension deal; mismatch risk

Eduard H. M. Ponds ABP, PO Box 4874, 6401 JP Heerlen, The Netherlands.

Tel: +3145 5797574; Fax: +31 45 5797258; E-mail: e.ponds@abp.nl

\section{Introduction and summary}

Pension funds worldwide currently are switching or considering switching to fair value principles. This switch implies a radical break with the actuarial approach Traditionally, the actuarial approach is based on book value principles and rules of thumb, such as a fixed 4 per cent 
actuarial discount rate. Risk is ignored or disguised. Actually, the actuarial approach leads to a self-constructed picture of the financial solidity of a pension fund without any link to financial markets.

The fair value approach implies market-based valuation of assets and liabilities so the balance sheet reflects true economic values. Furthermore, information on financial markets is used to arrive at an explicit analysis of the risk position of a pension fund. It also enables short-term and long-term policy questions to be analysed within one single framework. In other words, the fair value approach enables integral risk management.

The concept of 'mismatch risk' is the central risk measure in the fair value approach. Mismatch risk is defined as the standard deviation of the so-called 'excess return'. By 'excess return' is meant the difference between the return on assets and the return on the liabilities. There is a trade-off between excess return and mismatch risk. A higher expected excess return can only be realised by accepting more mismatch risk. The authors put forward that mismatch risk in the long run is lower than in the short run. There are two reasons for this. First, stocks have been characterised by mean reversion. Mean reversion implies that the average risk on an annual basis decreases when the investment period is extended. Secondly, in the long run a positive correlation can be observed between return on assets and return on liabilities. In the short term there is no such correlation.

A pension fund has a very long investment horizon (in fact indefinite) and is therefore in an excellent position to benefit from a decline of the mismatch risk in time. An important aspect of Dutch pension funds is risk-sharing between generations, so they are able to spread risk in time.
The long-run benefits in risk reduction and risk sharing stimulate pension funds to aim for long-term objectives in their investment policy. However, risk management in the short term remains important. A pension fund may always get involved in a situation of discontinuity, which can be the result for instance of bankruptcy of the sponsoring company, or of mergers and takeovers. Also the generational perspective is of importance. A fund with a serious funding shortage will not be attractive to young workers, because they know in advance that the scheme will harm their net lifetime income. A serious funding gap has to be solved by high contributions over a long period, so the present value of contributions to be paid will be in excess of present value of benefits to be received.

This paper will discuss three options to handle the high exposure to risk of short term underfunding. First, creating a floor by investing substantially in index-linked bonds. The importance of inflation-linked bonds for pension fund risk management is demonstrated. However, there is a very limited supply of these kinds of bonds. Hence, governments in Europe and elsewhere should be encouraged to issue (more) index-linked bonds. A second way is to hold a high solvency margin in order to absorb a fall in asset prices. However, it is very difficult to restore a surplus position when the pension fund has been hit by a severe fall in asset prices. This will imply high costs in terms of additional contributions by the sponsor and/or a reduction in defined benefits. The third way is to frame an explicit contract between stakeholders on the issue: which of the stakeholders, and to what extent, are participating in the risk of underfunding as well as overfunding? Such a contract is called a pension deal. The preferences of those stakeholders who are ultimately bearing the funding risk 
determine the exposure of mismatch risk and the degree of funding of the scheme.

The structure of this paper is as follows. It first looks at the concept of mismatch risk. Next it discusses return-risk trade-offs, which occur in the capital market, with a distinction being made between the short-run and the long-run. Taking a simple case as an example, it is shown that the long-run orientation of the investment policy leads to an improvement of the trade-off between return and mismatch risk in comparison with the short-run. The long-run benefits stimulate pension funds to aim for long-term objectives in their investment policy. However, risk management in the short term remains important. Finally, three options are discussed to control the short-term solvency position.

\section{Trade-off between excess return and mismatch risk}

The financing of pensions is based on funding. Pension promises to the participants have to be fulfilled by building up sufficient capital from contributions and investment returns. Higher returns imply less contribution, and the other way round.

The primary objective of a pension fund is to fulfill the pension promises at the lowest possible contribution rate with an acceptable level of risk. In fact this involves a trade-off between the expected excess return on the one hand and the exposure to mismatch risk on the other hand. Excess return is defined simply as the difference between the return on assets and the return on liabilities. Mismatch risk is defined as the uncertainty around the excess return. The fund may decide to construct the so-called perfect hedge portfolio. In the case of index-linked pension rights this perfect hedge portfolio will be made up entirely of indexed bonds. The characteristics of this mix are that the expected rate of return on assets is always equal to the rate of return on liabilities, so that the excess return, as well as the mismatch risk, is nil.

Addition of regular bonds and stocks to the portfolio results in an increase of the expected return on investment, so that it is to be expected that a lower contribution level will become possible, but at a higher mismatch risk.

\section{Return and risk in the short and the long run}

Risk analyses and ALM studies performed by pension funds are often based on the assumptions of constant expected returns, constant risks and constant correlations. An important implication of these assumptions is that the optimal mix for a one-year period is equal to the optimal mix taken for a multi-year period. In other words, the optimal asset allocation is the same for the short and long term.

\section{Return}

Ample literature has by now become available in which, in the authors' opinion, it is convincingly demonstrated that return levels which vary in time and which, given a sufficiently long horizon, are predictable to a certain extent on the basis of valuation ratios, must be dealt with. ${ }^{1}$

\section{Risk}

The length of the horizon is a significant factor for the risk profile of the various asset categories. The risk attaching to a one-year horizon need not be equal to the annualised risk attaching to a multi-year horizon.

The results of empirical studies 
indicate that long-term returns on investments in equities are characterised by mean reversion. With mean reversion the annual returns on equity investments fluctuate - with a certain degree of correlation (serial correlation) - around a long-term average. This means that the annualised risk in the case of equity investments can be assessed to be lower whenever a longer investment horizon is opted for. However, there are also economists and actuaries who state that the evidence on mean reversion depends very much on the chosen time period and the markets under consideration.

In the case of investment in fixed-income securities it appears, by contrast, that the annualised long-term risk is higher than the short-term risk. This phenomenon is referred to as mean-averting. The increase in time of the risk on fixed-income securities is to be attributed to the risk attached to reinvestment of interest and principal. The recognition of time-variation in risk should be reflected in time-variation of optimal portfolios.

\section{Correlation}

The correlation between changes in the value of assets and changes in the value of liabilities is of much significance to the mismatch risk for a pension fund.

Where the long term is concerned, a positive correlation is plausible. First of all, stocks will provide a long-term hedge for (wage) inflation. The future stream of nominal dividends is one of the driving forces of stock valuation. The growth of the liabilities as a result of indexation will then in the long term be partially matched by the upward revaluation of stocks. Empirically, the inflation hedge qualities of shares in the long term are difficult to prove. Two reasons can be given for this. Volatility of stock returns is much higher than the volatility of inflation, which makes it difficult to test for correlation between stock returns and inflation. In addition, there is the problem that in the past the inflation process has manifested itself as a series of inflation regimes which all have their own average level and volatility. However, if persistence in the inflation process is assumed and taken into account, then the correlation between inflation and shares in the long term does become clearer. The higher the inflation persistence, the better the performance of stocks as a hedge against inflation. ${ }^{2}$

With respect to nominal bonds and indexed liabilities, a positive correlation within a long-term setting is plausible as well. Movements in the real rate of interest will affect both bonds and liabilities. This is in particular the case in a low-inflation environment.

Market-based valuation of indexed pension rights is done on the basis of the real rate of interest. The nominal rate of interest is composed of the expected real rate of interest and the expected rate of inflation. The positive correlation between the nominal and the real rate of interest will be more pronounced in an economic regime with a low level of inflation than in an environment with a high level of inflation. In a high-inflation environment the effect of the inflation volatility will be dominant in relation to the real interest rate effect.

For the short term, any relationship between stocks and nominal wage growth will be absent. Bonds still may provide a hedge in a low-inflation environment, due to the co-movement in the real and nominal rate of interest. A pension fund with a heavy investment in bonds will be very vulnerable for a switch from a low-inflation to a high-inflation environment. The inflation expectations go up, nominal rate of interest will rise and so there is a low or even negative 
Table 1: Assumptions relating to return, risk and correlation: Short term and long term (low-inflation environment)

\begin{tabular}{|c|c|c|c|c|c|}
\hline Short term & Mean & Risk & $\begin{array}{l}\text { Correlation } \\
\text { stocks }\end{array}$ & $\begin{array}{l}\text { Matrix Bonds } \\
\text { long }\end{array}$ & Liabilities \\
\hline Stocks & 8.0 & 18.0 & 1 & & \\
\hline Long-term bonds & 5.0 & 8.0 & 0.2 & 1 & \\
\hline Liabilities return & 6.0 & 9.0 & 0 & 0.2 & 1 \\
\hline Wage inflation & 3.0 & 2.0 & - & - & + \\
\hline Price inflation & 2.0 & 1.5 & - & - & + \\
\hline Long term & Mean & Risk & $\begin{array}{l}\text { Correlation } \\
\text { stocks }\end{array}$ & $\begin{array}{l}\text { Matrix Bonds } \\
\text { long }\end{array}$ & Liabilities \\
\hline Stocks & 8.0 & 12.0 & 1 & & \\
\hline Long-term bonds & 5.0 & 10.0 & 0.2 & 1 & \\
\hline Liabilities return & 6.0 & 9.0 & 0.3 & 0.3 & 1 \\
\hline Wage inflation & 3.0 & 2.0 & - & - & + \\
\hline Price inflation & 2.0 & 1.5 & - & - & + \\
\hline
\end{tabular}

total rate of return on bonds. The value of indexed liabilities will go up because of higher indexation.

\section{Conclusion}

In short, from the above the authors conclude first that the optimal equity allocation for a long-term investor such as a pension fund will be higher than for a short-term investor. Stocks do mean-revert whereas bonds mean-avert. The longer the horizon, the more stocks become less risky, whereas bonds will become more risky.

Furthermore, in the long term a positive correlation between assets and liabilities can be expected. This leads to a reduction of the annualised mismatch risk and this reduction increases with the horizon. As a result, the trade-off between excess return and, respectively, contribution rate on the one hand and mismatch risk on the other, will improve in the longer run. These findings will be illustrated in the following with a simple case.

\section{Strategic investment portfolio}

What has been put forward in the foregoing can be illustrated with a simple case. This case is a highly stylised outline of the reality in order to highlight the major points. A higher degree of reality is possible of course, but this would only make the case more complex, without leading to fundamentally different insights.

Assume that a specific pension fund has formulated its expectations for the future, as has been set out in Table 1. These assumptions reflect the current environment for pension funds. A distinction is made between the short and the long term and the shading in the table indicates the changes for the long term in comparison with the short term.

\section{Expected values}

A low-inflation environment is assumed. The expected wage and price inflation are 3 per cent and 2 per cent, respectively. Return on long-term bonds is set at 5 per cent. The expected return on equity is 8 per cent, so the equity risk premium is equal to 3 per cent. ${ }^{3}$ Liabilities, L, have an expected growth rate $R_{L}$ of 6 per cent, which is based on an expected wage inflation rate of 3 per cent and an expected real rate of interest of 3 per cent. 
Table 2: Excess return and mismatch risk in the short and the long term

\begin{tabular}{cccccc}
\hline Mix bonds/stocks & RA & RL & RA - RL & $\begin{array}{l}\text { Mismatch risk } \\
\text { short term }\end{array}$ & $\begin{array}{l}\text { Mismatch risk } \\
\text { long term }\end{array}$ \\
\hline $100 / 0$ & 5.0 & 6.0 & -1.0 & 12.0 & 11.3 \\
$90 / 10$ & 5.3 & 6.0 & -0.7 & 11.8 & 10.8 \\
$80 / 20$ & 5.6 & 6.0 & -0.4 & 11.8 & 10.5 \\
$70 / 30$ & 5.9 & 6.0 & -0.1 & 12.0 & 10.4 \\
$60 / 40$ & 6.2 & 6.0 & 0.2 & 12.3 & 10.3 \\
$50 / 50$ & 6.5 & 6.0 & 0.5 & 12.9 & 10.4 \\
$40 / 60$ & 6.8 & 6.0 & 0.8 & 13.6 & 10.9 \\
$30 / 70$ & 7.1 & 6.0 & 1.1 & 14.4 & 11.4 \\
$20 / 80$ & 7.4 & 6.0 & 1.4 & 15.3 & 12.0 \\
$10 / 90$ & 7.7 & 6.0 & 1.7 & 16.4 & 12.7 \\
$0 / 100$ & 8.0 & 6.0 & 2.0 & 17.5 & \\
\hline
\end{tabular}

\section{Risk}

The risk per category is given in terms of standard deviations. For the asset categories a higher risk brings the prospect of a higher expected return. A distinction has been made between equity risk in the short and in the long term. The annualised risk on equity is lower in the long term than in the short term because of mean reversion. The risk on equity in the long term is assumed to be equal to 12 per cent, while in the short term it is 18 per cent. The reinvestment risk of bonds results in an increase of the risk in the long term from 8 per cent to 10 per cent.

The volatility of the liabilities can be traced back to the volatility of the real rate of interest and the wage inflation. The pension liabilities may relate to benefits that will become payable in the distant future (say within the period of the next 80 years). The weighted average duration of the pension rights in the case of a typical pension fund is of the order of 15 to 20 years. That is why relatively small movements in the real rate of interest and wage inflation may have a relatively heavy impact on the provision for pension liabilities. The standard deviation of this liability return is consequently relatively high and it has here been put at 9 per cent. ${ }^{4}$

It should be noted that for the short term a low correlation is assumed between bonds and liabilities, reflecting that in a low-inflation environment bonds and liabilities are both affected by movements in the real rate of interest. For the long term, stocks provide a hedge for wage-indexed liabilities.

Table 2 below shows the relation between the asset mix, the level of the returns on invested capital $R_{A}$, the liability return $R_{L}$ and the excess return $\left(\mathrm{R}_{\mathrm{A}}-\mathrm{R}_{\mathrm{L}}\right)$, and mismatch risk in the short and in the long term. Figure 1 shows the trade-offs ('efficient sets') between excess return and mismatch risk for the short term and for the long term. From this figure it can be seen at a glance that a long-term orientation of the investment policy results in an improvement of the trade-off between return on the one hand and mismatch risk on the other.

It may be noted that a pension fund has a huge exposure to mismatch risk, even with a 100 per cent mix of nominal bonds. Furthermore, this simple case with realistic assumptions shows very clearly that a pension fund with indexed benefits needs to invest quite heavily in equities (at least 40 per cent) to have a prospect of a positive excess return. 


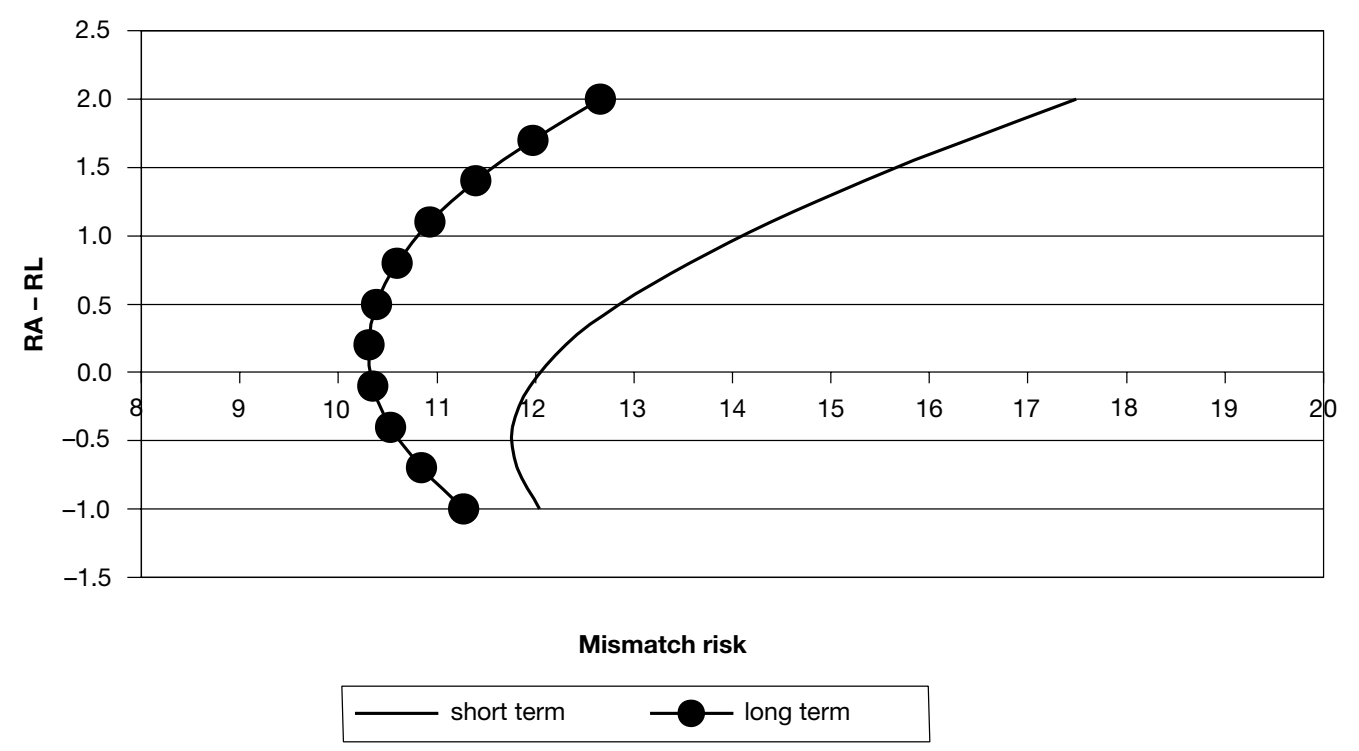

Figure 1: Trade-off between return and mismatch risk

\section{Solvency}

A pension fund cannot avoid mismatch risk and is therefore exposed to solvency risk that may lead to a situation of serious underfunding. Traditionally, in the Netherlands the pension laws and the regulating authorities have focused on the short-term solvency position. ${ }^{5}$ A fund is seen as solvent if its capital is at all times sufficient to allow a transfer of the liabilities to a third party, for instance to another pension fund in the event of a merger or a takeover, or to an insurance (or reinsurance) company. The solvency situation may be controlled by investing substantially in index-linked bonds or by aiming at holding a large funding surplus position. However, these two solutions are hampered by serious problems.

Therefore the framing of an explicit pension deal is proposed as a third way.

\section{Option I: Index-linked bonds}

Index-linked bonds (ILB) were not included in the preceding analysis. It is a well known result that a large availability of index-linked bonds will improve considerably the risk management practice of pension funds. These bonds provide a hedge for the indexed pension liabilities, so they reduce the mismatch risk of the fund. Figure 2 shows the potential of ILB for pension fund risk management. Two types of ILB are distinguished, the so-called wage-indexed bonds and the price-indexed bonds. The return on price-indexed bonds is the sum of the real coupon plus the actual price-inflation. It is assumed that the expected return on price-indexed bonds is equal to the expected return on regular bonds. Also the expected return on wage-indexed bonds also is set equal to the expected return on regular bonds. Wage growth can be decomposed in real growth plus price-inflation. Therefore, the real coupon of the wage-indexed bonds has to be lower than the real coupon of price-indexed bonds in order to warrant that the expected nominal returns on the different types of bonds are all equal. A very important characteristic of wage-indexed bonds is 


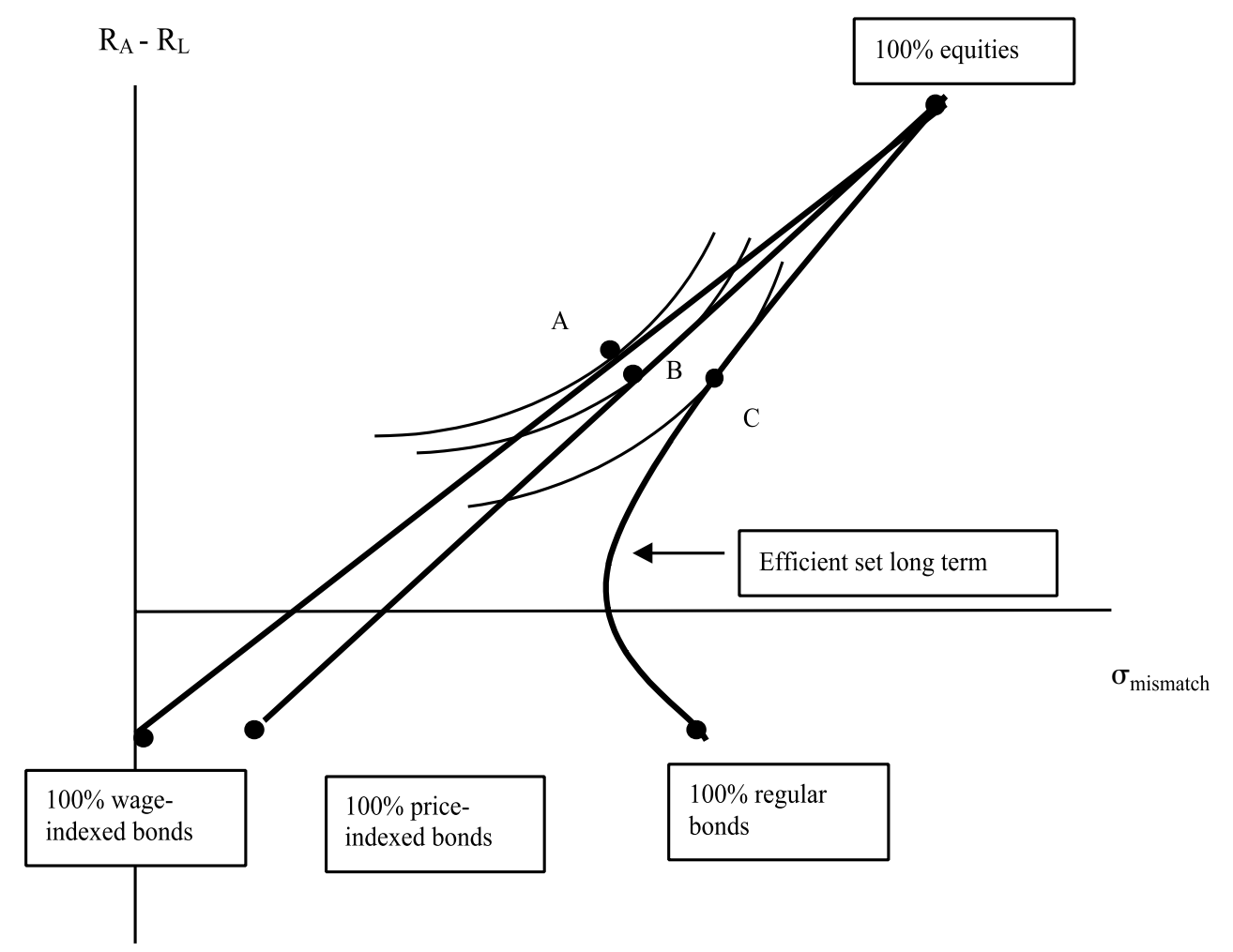

Figure 2: Efficient sets

that the offered return matches the return on wage-indexed liabilities, so a pension fund with an asset mix composed of 100 per cent wage-indexed bonds is free of mismatch risk. When the asset mix is composed of price-indexed bonds, then mismatch risk will also be reduced considerably, but not completely because these bonds provide no hedge against real wage growth volatility. Apart from the efficient set consisting of regular bonds and equities, we can distinguish an efficient set with price-indexed bonds and equities and an efficient set with wage-indexed bonds and equities. It is plausible to assume that the objective function of a pension fund is positively related to the term excess return and negatively to the term mismatch risk. Figure 2 then shows that combinations of wage-indexed bonds and equities are superior to combinations of price-indexed bonds and equities and also superior to combinations of regular bonds and equities.

The risk-reducing capacity of index linked bonds (ILB) clarifies how important it is that more of these assets are issued. This will contribute to the sustainability of funded defined benefit plans. In many countries in Europe, governments consider the transition from pay-as-you-go pensions to funded pensions, primarily defined contribution plans. ILB will also be of considerable significance for defined contributions plans in order to reduce the investment risk in the retirement period and the pre-retirement plans.

However, the world market of index-linked assets is too small to be of real interest for pension plans. Table 3 
Table 3: Comparison assets pension funds and large inflation-indexed bonds markets

\begin{tabular}{lclr}
\hline Inflation-indexed markets & (\$USbn) & Pension fund capital (\$USbn) \\
\hline Canada & 11 & Netherlands & 440 \\
France & 19 & UK & 1261 \\
Sweden & 12 & USA & 8078 \\
UK & 103 & Canada & 607 \\
US & 133 & Japan & 1926 \\
Total & $\mathbf{2 7 8}$ & & \\
\hline February 2002 & & Ultimo 2000 & \\
Source: Barclays Capital & & Source: Pensions \& Investments
\end{tabular}

shows that the world market size of inflation-indexed bonds amounts to more or less US $\$ 270$ bn in May 2001. The size of the pension funds in the Netherlands already amount to more than US $\$ 400$ bn in spring 2002.

\section{Option II: High surplus}

A second way to control short-term risk of underfunding is to hold a minimum surplus position in order to absorb a fall in asset prices so that the funding ratio will remain above 100 per cent. The Appendix sets out how a minimum margin can be determined. All Dutch pension funds follow this route to control solvency risk. The Dutch supervisor also advocates this approach. However, the authors have serious doubts about this approach, because it may harm the long-term durability of the Dutch pension scheme. The main problem is how to restore an empty buffer after the fund has been hit by a serious fall in asset prices or by a high increase in indexation burden due to high wage increases.

One way to restore an insufficient solvency position is to limit the exposure to mismatch risk because this will lower the required minimum size of the solvency margin. For instance, a switch from a risky asset mix to a more conservative asset mix will result in lower solvency requirements. Such a myopic investment policy will entail negative effects. So far in this paper it has been shown that pension funds have to accept high exposure of mismatch risk in order to realise at least a positive excess return. This is a necessary condition for the growth rate of assets to keep pace with the growth rate of liabilities. So the switch to a more conservative asset mix is not a durable solution. It may be of help for the short term, but it will undermine the long-term solvency position.

Higher contributions may also close the solvency gap. However, this will imply very high additional contributions; too high to be of help in real life. To restore a 1 per cent-point fall in the funding ratio requires for a typical Dutch fund 3 per cent-point to 5 per cent-point additional contributions. The recent decline in funding ratio of Dutch funds range from 20-40 per cent. Hence, a short-term recovering of the solvency position by additional contributions is not feasible.

So, whenever a pension fund encounters a situation of a severe funding gap, then recovery will be difficult. A situation with a problematic solvency position will cause lots of difficulties. First, the supervisor will force the pension fund to take measures to restore solvency. Secondly, conflicts may arise between stakeholders as to the issue: who has to fill the funding gap? 
Therefore it is better to admit in advance that a pension fund is not able to guarantee that the funding ratio will remain above 100 per cent. The aim of having a sufficiently high funding ratio can be replaced by an explicit pension deal. This is the third solution.

\section{Option III: Towards an explicit pension deal}

A pension deal is explicit when there is full clarity on the three aspects below:

1 Pension plan: What is the defined promise?

2 Funding: What are the aims in the process of funding, ie what is the aimed return on investments, the aimed contribution rate and what is the tolerated level of mismatch risk?

3 Risk: Which of the stakeholders and to what extent take part in bearing risk?

As to the third aspect, two extreme situations can be distinguished.

\section{Contributions}

The sponsors bear all risk, whereas the indexation of accrued benefits and the build-up of new benefits take place according to the conditions of the pension plan. This is a defined benefit scheme in its pure form. The participants have full certainty as to their benefits. The contribution rate is uncertain depending on how the funding ratio is hit by economic risks (asset prices and wage and price inflation).

\section{Indexation}

The contribution rate is fixed at a certain level (for example, the actuarial cost price). Risk is absorbed by adjusting the indexation of the liabilities of the participants. A low funding ratio will imply a low indexation or no indexation at all, and it may lead to a decrease in accrued benefits. A high funding ratio will lead to compensating indexation or even additional indexation. This risk-bearing alternative implies a change from a defined benefit scheme to a collective defined contribution scheme.

In real practice, it is more likely that the risk-sharing rules are somewhere between these two extremes.

Almost all Dutch pension funds lack such an explicit pension deal. Usually the contract on risk bearing is implicit of nature. This may easily lead towards asymmetry in the pension fund policy in relation to the funding position. In the late 1990s, pension funds experienced huge surpluses that have been used for shortages in contributions and improvements of the pension benefits. After the dramatic fall in stock prices in recent years, most Dutch pension funds are struggling with underfunding. The supervisor insists on a recovery of the solvency situation in the short term; however, stakeholders disagree on who has to pay. The implicit nature of the contract may be harmful to the continuity of the contract.

However, the current situation can be regarded as a challenge to reach a more explicit contract of risk-sharing. Such an explicit pension deal will prevent policy inertia and conflicts between stakeholders, because it is always clear who has to pay, when, and to what extent, in a shortage situation. It should also be clear who also will benefit, when, and to what extent, in the case of a large overfunding. ${ }^{6}$ Furthermore, the authors advocate that the stakeholder who ultimately bears the funding risk this may be either the sponsor or the collectivity of participants or a combination of them - has to decide on the funding policy. The risk-bearing stakeholder is then able to relate the funding policy to his preferences. 
Table 4: Seven critical questions for an explicit pension deal ${ }^{7}$

\begin{tabular}{|c|c|}
\hline Assets & Liabilities \\
\hline \multirow{2}{*}{$\begin{array}{l}\text { 5. What is the risk-free asset mix that } \\
\text { provide a perfect match with liabilities? } \\
\text { 6. Should pension fund undertake asset mix } \\
\text { policy risk? } \\
\text { 7. Should the plan undertake active } \\
\text { management risk? }\end{array}$} & $\begin{array}{l}\text { 1. What is the benefit promise? } \\
\text { 2. What is the value of defined benefits? }\end{array}$ \\
\hline & $\begin{array}{l}\text { Surplus } \\
\text { 3. What is the target funding ratio? } \\
\text { 4. How are balance sheet surpluses and } \\
\text { losses allocated between stakeholders? } \\
\text { Who owns the surplus on termination? }\end{array}$ \\
\hline
\end{tabular}

An explicit pension deal may also imply a completely different role for the supervisor. Whenever an explicit pension deal is in force, the supervisor has to check that the execution of the pension fund is in accordance with the content of the deal. There is no longer a need to formulate criteria as to the minimum margin. It is the ultimate risk-bearer who has to decide on the issue of aimed funding ratio.

Ambachtsheer and Ezra ${ }^{7}$ suggest a programme of questions to arrive at an explicit pension deal. Table 4 is a representation of their proposal. These questions may be of help to clarify the main topics in the pension fund arrangement. If a pension fund is going to create value for its stakeholders, the fiduciary of the fund must actually be clear as to what the pension promise is and who the risk-bearers are.

\section{Acknowledgment}

We thank Keith Ambachtsheer, Jean Frijns and Luis Viceira for comments on an earlier version.

\section{References}

1 See for instance Campbell, J. Y. and Viceira, L. M. (2002) 'Strategic asset allocation: Portfolio choice for long-term investors', Oxford University Press, Oxford.

2 See Schotman, P. C. and Schweitzer, M. (2000) 'Horizon Sensitivity of the Inflation Hedge of Stocks', Journal of Empirical Finance, Vol. 7, pp. 301-315.

3 We acknowledge that currently a debate is going on as to the size of the equity premium for the coming years. The 3 per cent assumption may indeed be seen as quite high. However, a lower (or higher) equity premium will have no impact on the argument of the paper.

4 This $9 \%$ is calculated with the following expression: $\sigma_{\text {liabilities }}=\mathrm{D}^{*} \sigma_{r r}+\sigma_{\text {wage }}$. The term $\mathrm{D}$ represents the duration of the laibilities, the term $\sigma_{r r}$ stands for the risk (standard deviation) in the real rate of interst and $\sigma_{\text {wage }}$ for the risk in wage growth. The volatility in the expected real rate of interest rate is quite low and it has been set equal to 0.4 per cent. Let duration be equal to 17.5 years (this is more or less the duration of a typical Dutch pension fund with indexed liabilities. The volatily in wage growth is set equal to 2 per cent. This leads to a volatility in liabilities of $9 \%(=17.5 * 0.4 \%+2 \%)$.

5 The Dutch supervisor is currently developing a revised framework. Fair value and risk analysis are prominent features of the new model. Elaboration of methods and techniques, as well as the defining of standards will take place within the next few years. The supervisor, the 'Pensioen- \& Verzekeringskamer' (pensions and insurance supervisory authority of the Netherlands) has recently published the basic principles for this new framework, named: the Financial Testing Framework. See http://www.pvk.nl/engels/index_general.html.

6 The deal may also be important to check - at least on an ex ante basis - that the advantages of participation are on balance higher than the disadvantages. Then the participation of the various stakeholders is ensured, as it is in the interest of all of them that the pension fund remains in existence. Main advantages of participation are the prospect of an insured wage-related pension, a low contribution rate and low implementation costs. As main disadvantages one can distinguish volatile contribution rate, lack of full freedom of choice and ex-post income transfers between the parties involved.

7 Ambachtsheer, K. P. and Ezra, D. D. (1998) 'Pension Fund Excellence, Creating Value for Stakeholders', John Wiley \& Sons, New York.

8 Or a variant of the probability of underfunding, for instance the size-weighted probability of underfunding or the downside deviation risk. 


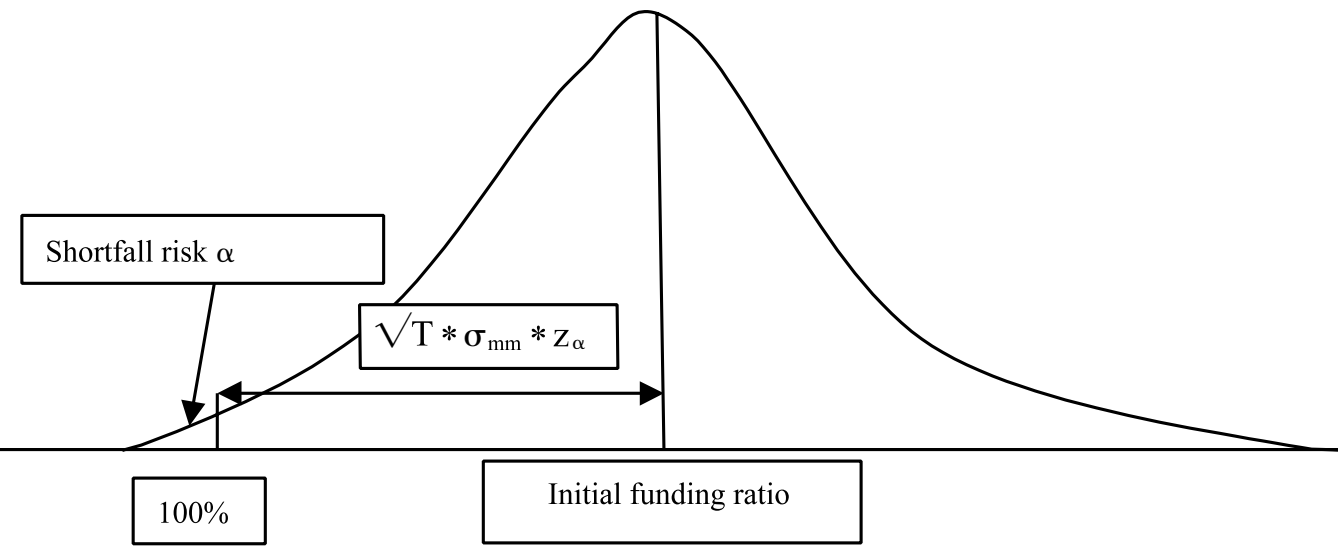

Figure 3: Probability distribution funding ratio end of year $\mathrm{T}$

9 This formula does not take into account the effect of the increment of the funding ratio due to the expected exces return: initial funding ratio $=100 \%$ + margin $-/-$ increment of excess return. However, the latter term can be taken to be zero, for two reasons: in case the actual funding ratio is equal to the initial funding ratio, then the increment of the funding ratio is freely available and can for instance be used for premium reduction or pension improvement.

\section{Appendix: Minimum solvency margin}

This paper has discussed the holding of a minimum solvency margin as one way to control short term risk of underfunding. Here the minimum solvency margin in a fair value context is derived.

The funding ratio $T$ years from now is uncertain and can be described on the basis of a probability distribution. In the short term the probability distribution can be characterised as a normal distribution. The spread in the distribution is mainly determined by the mismatch risk. The mismatch risk is nil if all the resources of a given fund are invested in indexed bonds. The addition of regular bonds and shares results in more excess return, but at the same time in a higher mismatch risk as well. The crucial issue now is the question which shortfall $\operatorname{risk}^{8} \alpha$ after a period of $\mathrm{T}$ years is acceptable as a maximum. This choice is determinative of the initial funding ratio or the required solvency margin.

The initial funding ratio can be determined by means of the following formula, ${ }^{9}$ where the volatility in the funding ratio increases in time proportionally to the square root of the forecast period $\mathrm{T}$ :

Initial funding ratio

$$
\begin{aligned}
& =100 \%+\text { margin } \\
& =100 \%+\sqrt{\mathrm{T}} * \sigma_{\mathrm{mm}} * \mathrm{z}_{\alpha}
\end{aligned}
$$

where:

$$
\begin{aligned}
\mathrm{T}= & \text { forecast period } \\
\sigma_{\mathrm{mm}}= & \text { mismatch risk (=standard } \\
& \text { deviation of extra return } \\
& \text { relative to the liabilities) } \\
\mathrm{z}_{\alpha}= & \text { number of standard deviations } \\
& \text { away from the average, given } \\
& \text { the accepted shortfall risk } \alpha
\end{aligned}
$$

The above can be illustrated by Figure 3 . Now, with alternative values taken for $\mathrm{T}, \alpha$ and $\sigma_{\mathrm{mm}}$ the size of the required margin can be determined for the pension fund presented in the case study above. 
Table 5: Minimum solvency margin for different combinations of horizon ( $T$ ) and probability of underfunding $\alpha$, for a given mix of $50 \%$ shares and $50 \%$ long-term bonds

\begin{tabular}{llcl}
\hline Margin & Period $\mathbf{T}$ & Probability $\boldsymbol{\alpha}(\%)$ & Mismatch risk $\boldsymbol{\sigma}$ \\
\hline 16.4 & 1 & 10 & 12.9 \\
21.2 & 1 & 5 & 12.9 \\
29.9 & 1 & 1 & 12.9 \\
38.8 & 1 & 0.1 & 12.9 \\
\hline 28.5 & 3 & 10.0 & 12.9 \\
36.7 & 3 & 5 & 12.9 \\
51.9 & 3 & 1 & 12.9 \\
67.2 & 3 & 0.1 & 12.9 \\
\hline 36.8 & 5 & 10 & 12.9 \\
47.4 & 5 & 5 & 12.9 \\
66.9 & 5 & 1 & 12.9 \\
86.8 & 5 & 0.1 & 12.9 \\
\hline
\end{tabular}

Table 6: Minimum solvency margin for different mixes, with a horizon of three years and a $5 \%$ probability of underfunding

\begin{tabular}{lllll}
\hline Margin & Period T & Probability $\boldsymbol{\alpha}(\%)$ & Mismatch risk $\boldsymbol{\sigma}$ & Mix stocks/bonds \\
\hline 34.2 & 3 & 5 & 12.0 & $30 / 70$ \\
35.2 & 3 & 5 & 12.3 & $40 / 60$ \\
36.7 & 3 & 5 & 12.9 & $50 / 50$ \\
38.8 & 3 & 5 & 12.6 & $60 / 40$ \\
41.1 & 3 & 5 & 14.4 & $30 / 70$ \\
\hline
\end{tabular}

Three variants as regards to the horizon are distinguished:

$$
\begin{aligned}
& \mathrm{T}=1 \text { (in line with the new solvency } \\
& \text { assessment of Pension and } \\
& \text { Insurance Chamber); } \\
& \mathrm{T}=3 \\
& \mathrm{~T}=5
\end{aligned}
$$

For the probability of underfunding $\alpha$, 10 per cent, 5 per cent, 1 per cent and 0.1 per cent are chosen. On the basis of these values, the following values for $\mathrm{z}$ are obtained:

\begin{tabular}{ll}
\hline$\alpha(\%)$ & $\mathrm{z}_{\alpha}$ \\
\hline 10 & 1.28 \\
5 & 1.65 \\
1 & 2.33 \\
0.1 & 3.02 \\
\hline
\end{tabular}

For the various combinations of $\mathrm{T}$ and $\alpha$ the required solvency margin is calculated, on the basis of an investment portfolio, which is made up of 50 per cent equities and 50 per cent long-term bonds. This mix gives a short-term mismatch risk of 12.9 per cent. The results of these calculations are presented in Table 5. It can be seen that the margin increases accordingly as the period becomes longer. This is due to the accumulation of uncertainty as the horizon is extended. The margin becomes larger as the allowable probability of underfunding becomes smaller.

Table 6 shows the effect of variants in the investment mix on the margin. The mix is determinative of the level of the mismatch risk. The calculations have been done for a combination of a horizon of three years and 5 per cent as the acceptable probability of underfunding. The figures in Table 5 show the increase of the margin at a higher mismatch risk. 